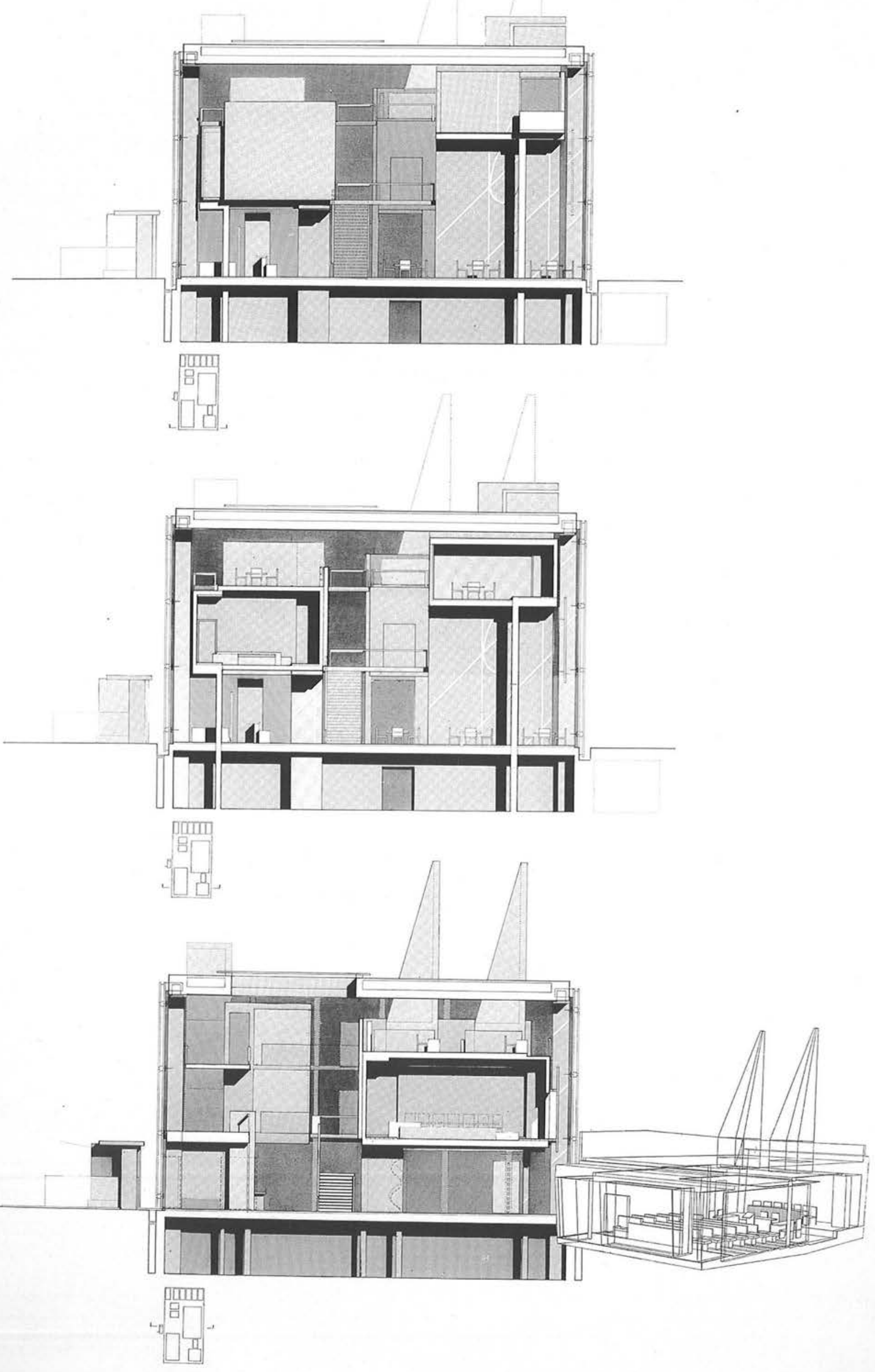




\section{MARK GOULTHORPE}

\section{Reykjavik High Court Iceland}

This project is the competition entry for the Supreme Court of Iceland in Reykjavik. It focusses on a 'public' architecture, but one which is still seemingly shrouded in privacy, for the courthouse (the chamber where the law of the land - the foundation-stone of democracy - is established) is in Iceland, certainly one of the most important public institutions, second only, perhaps, to Parliament itself.

Yet, when I went to Iceland (to this most democratic and egalitarian of societies), I was astonished to read the brief which specified (quite literally) that the building be of concrete construction, and divided completely in two with the judiciary entirely separated from the public who I had supposed they were to represent.

This was not to be a courthouse where people are tried (which one might imagine still needs such distinction, such reinforcement of power), but a debating chamber, open to all, where the public might come to witness and comprehend the process by which the law evolves and which gives shape to their liberty.

We might speculate, with Nietzsche, that every advance in society, every heightening of its morality, is marked by an opening of its systems of justice, as it resists, to an ever greater degree, the ethic of revenge. The law, and transgressions of the law, come to be seen in this movement increasingly at a social rather than an individual level. Notions of 'guilt' (and even punishment) are dissipated into social debate and society reflects upon itself.

This, as I see it, is the very substance of the supreme court. It is not a place of division and privilege, but of open and just social commentary; the courthouse as a quite public sanatorium of the conscience.

Our proposal, then, is a High Court for the 21st Century. It anticipates this continuing desire for refinement, this straining towards an ideal of open justice, and it does so in quite marked opposition to the constraints of the brief.

The building is simple. It is open and transparent in both its organisation and its materials as it looks for an increased openness and clarity, as justice brought to light. It is envisaged as an open public forum, a great moot hall filled with filtered natural light within which are placed the various elements of the courthouse.

Discrete scupltural forms float in open space, shrouding the judicial functions within, but clearly open to view. Such conceptual clarity extends even to the separation of judges and public. This is achieved simply and effectively by a series of walkways in space which allow one to glimpse the judges as they circulate such that the public can witness and comprehend the full functioning of the court, a theatre of justce.
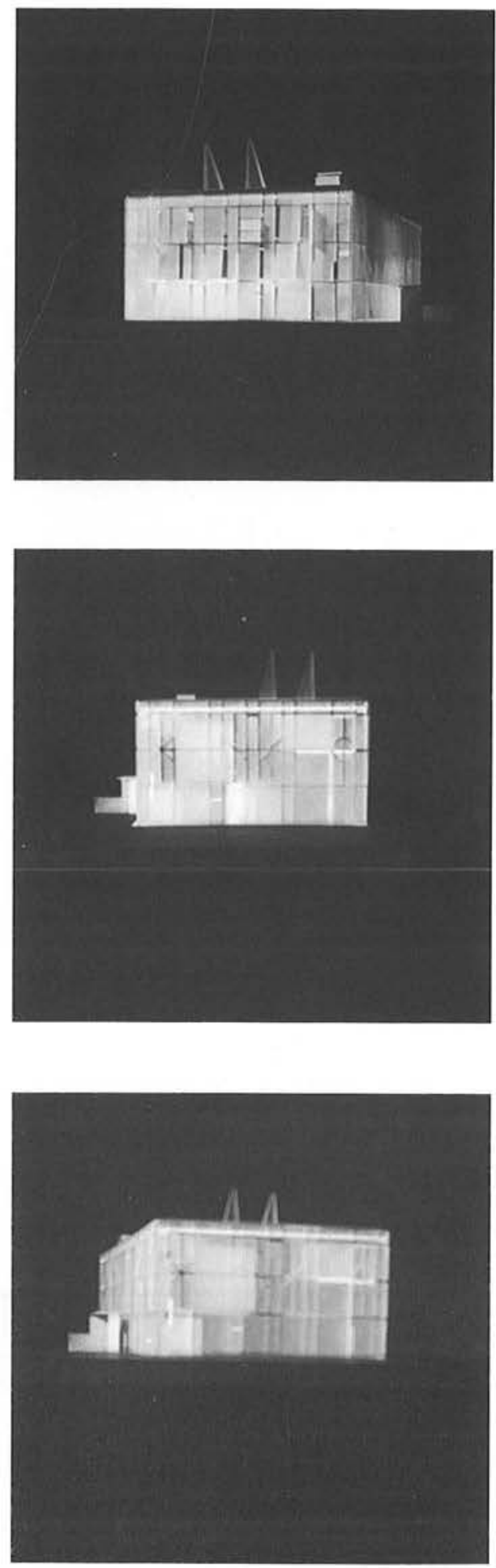
The courtrooms themselves, the point of union between lawyers, judges and public, continue this ideal of openness. Elevated boxes are flooded with daylight from skylights which pierce up through the plane of the roof. They are calm, neutral spaces, folded combinations of concrete, plaster and wood, stripped of all symbolism or hierarchy. They are simple and elegant (both conceptually and physically), and they impart a dignity and equality to this highest court of the people.

Externally the building is a simple crystalline cube, a translucent and fragile envelope enclosing more solid and elemental forms (perceived as shadowy forms) within. Its glass skin is sheathed with a delicately perforated metallic surface, a filter which plays continuously with the subtle and changing light of Iceland - a solid luminous form, in the dark winter, glowing from within, and in the surreal summer light, an ambiguous and reflective surface.

The courthouse compliments the delicacy and lightness of the adjacent library with a contemporary aesthetic and finesse. The form of the building duplicates that of the existing library. The rhythmic pattern of its metallic skin is generated from the library's geometry and is incised with the abstracted forms of ancient runes (the primordial root of all writing and law).

The two buildings read as twin pavilions of light - one white, the other metallic, set against the dark and powerful form of the art deco theatre behind. Set on a hill overlooking the harbour, the two buildings begin to define a civic presence, the library already destined to house the President's offices.

The courthouse draws inspiration from the generic simplicity and the utilitarian and lightweight construction of contemporary Icelandic architecture. Fragile but pure forms are placed delicately into the savage expanse of the volcanic landscape. They draw from the almost mystical qualities of this strange land: the subtle ambiguity of the northern light, the eerily illumination of the vast Atlantic skies, and the harsh rawness of natural materials - the rough concrete shrouded by a cold and brittle metallic veil.

There were two architects on the jury, and three members of the judiciary, and what, for me, was interesting, was that it was the architects who liked the project and apparently staked their claim on it. The lawyers hated it to the point where they threatened to dissolve the jury.

This was completely the reverse of what I had expected since I had blithely assumed that the lawyers would appreciate this search for a form that mirrored, as it were, this opening of the judicial system which championed the Supreme Court as the haven of democratic law.

This leads me to question our potential to effect change through architecture, to open the way, as it were, to an increasing liberty. It is a question succinctly posed, and effectively answered, I think, by Michel Foucault:

"Men have dreamed of liberating machines. But there are no machines of freedom, by definition. This is not to say that the exercise of freedom is completely indifferent to spatial distribution, but it can only function when there is a certain convergence....

Where liberty is effectively exercised, one finds ... that this is not owing to the order of objects, but, (once again), owing to the practice of liberty..."

So there may, in fact, always be, a certain number of projects whose aim is to modify some constraints, to loosen, or even break them. But none of these projects can, simply by their nature, assure that people will have liberty automatically:

"I think it [architecture] can and does produce positive effects when the liberating intentions of the architect coincide with real practice of people in the exercise of their freedom."

In Reykjavik, it became apparent that our liberating intentions simply did not coincide with such practice (or at least did not correspond with the perception of such practice). It scarcely matters if, in our opinion, that resulted from a certain blindness. The fact of the matter was, that there was not a 'convergence'. That is not to say that we shouldn't have attempted to 'modify some constraints, to loosen or even break them', for I think the aspiration to an increased openness in the judicial system was a good one.

One does not hesitate to have the courage of one's convictions (that, I am afraid, is our inheritance) which means that one must be willing to have one's ideas rejected, in the hope that, if nothing else, they might begin to shift perception. 

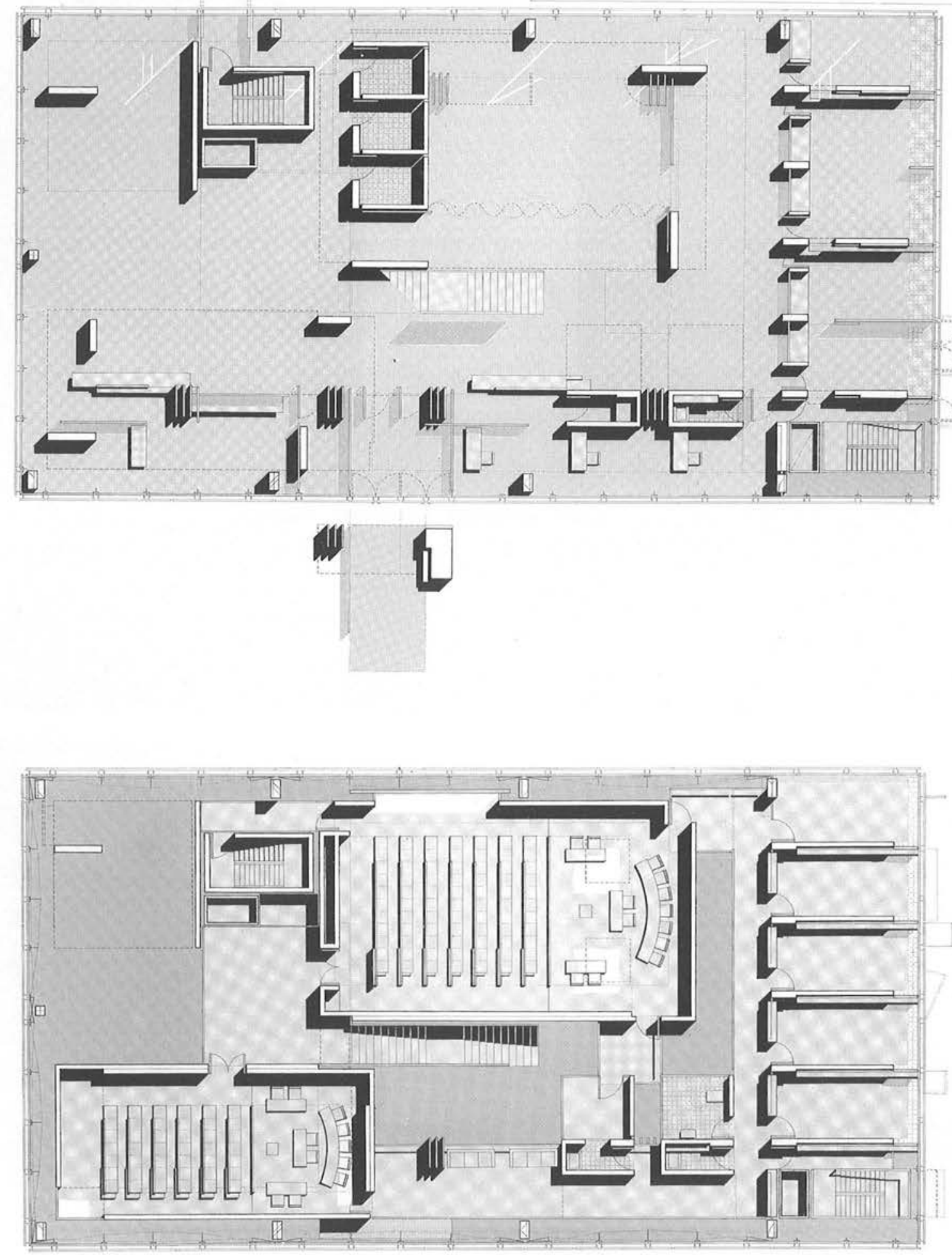